\title{
Heat Treatment Inhibits Mango Chilling Injury
}

\author{
T. Gregory McCollum, Salvatore D'Aquino ${ }^{1}$, and Roy E. McDonald \\ U.S. Department of Agriculture, Agricultural Research Service, U.S. \\ Horticultural Research Laboratory, 2120 Camden Road, Orlando, FL 32803
}

Additional index words. Mangifera indica, ethylene, respiration, firmness, color, soluble solids concentration, titratable acidity

\begin{abstract}
Keitt' mango (Mangifera indica L.) were kept at 38C for 0, 24, or 48 hours before storage at $5 \mathrm{C}$ for 11 days. Nonheated fruit developed severe rind pitting and discoloration, whereas chilling injury symptoms decreased with increased duration at 38C. Respiratory rates were slightly higher in nonheated than in heated fruit. Nonheated fruit produced a transient burst of ethylene evolution following transfer to 21C; heated fruit did not produce a similar burst. Firmness was similar in nonheated and heated fruit at the time of transfer to $21 \mathrm{C}$ for ripening, but was slightly higher in nonheated fruit after 3 and 6 days of ripening. Soluble solids concentration was higher in heated than in nonheated fruit at the time of transfer to $21 \mathrm{C}$, but was similar after 9 days at 21C. Commission Internationale de l'Eclairage $a^{*}$ and $b^{*}$ flesh values were higher in heated than in nonheated fruit. Results of this study indicate that mango tolerance to chilling temperatures may increase after prestorage heat treatment.
\end{abstract}

Mangos are a tropical crop subject to chilling injury (CI) when stored below 10C (Couey, 1986; Hatton et al., 1965). CI symptoms in mangos include rind discoloration, pitting, uneven ripening, poor color and flavor, and increased susceptibility to decay (Hatton et al., 1965; Kane et al., 1982; Medlicott et al., 1990). Mango tolerance to chilling changes during ripening (Medlicott et al., 1990) and is influenced by ripening temperature (Thomas and Joshi, 1988). Due to mango sensitivity to CI, mangos cannot be stored at low temperatures and, consequently, have a short postharvest life. Recently, high-temperature (36 to 40C) treatments have increased the chilling tolerance of chilling-sensitive tissues (Klein and Lurie 1991; Lafuente et al., 1991; Lurie and Klein, 1991). Tomato (Lycopersicon esculentum Mill.) fruit kept at 36 to $40 \mathrm{C}$ for 3 days did not develop CI and ripened normally following storage at 2C for 3 weeks (Lurie and Klein, 1991). Hirose (1985) reported that prestorage heating at 36 to $40 \mathrm{C}$ for $24 \mathrm{~h}$ increased cucumber (Cucumis sativus L.) tolerance to chilling temperatures. Increasing the tolerance of chilling-sensitive commodities would be desirable for several reasons:

- Chilling-sensitive products could be stored at lower temperatures for longer periods without a loss of quality.

Received for publication 30 Mar. 1992. Accepted for publication 12 Nov. 1992. Mention of a trademark, warranty, proprietary product, or vendor does not constitute a guarantee by the U.S. Dept. of Agriculture and does not imply its approval to the exclusion of other products or vendors that may be suitable. The cost of publishing this paper was defrayed in part by the payment of page charges. Under postal regulations, this paper therefore must be. hereby marked advertisement solely to indicate this fact.

${ }^{1}$ Visiting scientist from the C.N.R. Instituto Arboricoltura Mediterranea, Via E. De Nicola 1, 07100 Sassari, Italy.
- Mixed storage of commodities with heretofore incompatible storage temperature requirements may become possible.

- Low-temperature insect disinfestation treatments could be used with less danger of CI (Klein and Lurie, 1991).

The objective of our study was to determine if high-temperature treatment would improve mango fruit chilling tolerance.

Mature 'Keitt' mango fruit were obtained at harvest from a commercial packinghouse in Dade County, Fla. The fruit were transported in an air-conditioned van to the laboratory in Orlando, Fla. On arrival, the fruit were numbered, weighed, and sorted into five groups of 50. One group was placed immediately in storage at $5 \mathrm{C}$. Two other groups were placed in a room maintained at $38 \mathrm{C}$, relative humidity $(\mathrm{RH})>90 \%$. Fruit were removed from the $38 \mathrm{C}$ room after 24 or $48 \mathrm{~h}$, weighed, and placed at 5C, $85 \%$ to $90 \%$ RH. Fruit were transferred to $21 \mathrm{C},>90 \% \mathrm{RH}$ after 11 days at $5 \mathrm{C}$. At the time of transfer to $21 \mathrm{C}$, the fruit were weighed and rated visually for $\mathrm{CI}$ using a scale of 0 to 4 ; 0 indicated no injury and 4 indicated severe injury (discoloration and rind pitting). The fruit were rated for CI again after $48 \mathrm{~h}$ at $21 \mathrm{C}$.

Five fruit from each treatment were selected at random to determine respiration and ethylene evolution rates. Individual fruit were sealed in 4-liter glass jars; following $1 \mathrm{~h}$ of incubation, a sample of headspace atmosphere was collected and analyzed for carbon dioxide by gas chromatography. The jars were opened, ventilated with a stream of air, and resealed. A sample of headspace atmosphere was collected after $2 \mathrm{~h}$ of incubation and analyzed for ethylene by gas chromatography. Before being sampled, the headspace atmosphere in the jars was agitated 10 times with a 60 -cc syringe. Gas analyses were conducted every $6 \mathrm{~h}$ for 48 $\mathrm{h}$ after transfer to $21 \mathrm{C}$ and then every $24 \mathrm{~h}$.

At the time of transfer to $21 \mathrm{C}$, and at 3-day intervals thereafter for 9 days, five fruit were selected at random from each treatment for destructive quality analyses. Flesh color was measured on two pared cheeks of each fruit using a Minolta CR-200 chromameter (Minolta, Osaka, Japan) using the Commission Intemationale de l'Eclairage (CIE) (L*, $\mathrm{a}^{*}$, and $\left.\mathrm{b}^{*}\right)$ color scale. Flesh firmness was measured using a testing instrument (Instron Universal, Canton, Mass.) equipped with a 1.1-cm-diameter probe; three measurements were made on each fruit cheek. Total soluble solids concentration (SSC) in a sample of juice squeezed from the pulp was measured using an Abbe (A.O. Scientific Instruments, Keene, N.H.) refractometer. A representative pulp sample was frozen and stored at $-20 \mathrm{C}$ to measure $\mathrm{pH}$ and titratable acidity.

Nonheated mango fruit stored at $5 \mathrm{C}$ for 11 days developed severe CI (Table 1), which was manifested as rind discoloration and pitting. Heating significantly reduced CI.

Carbon dioxide evolution rates from mango fruit were lowest at the time of transfer to $21 \mathrm{C}$, increased in a typical climacteric pattern, and then decreased (Fig. 1, top). Carbon dioxide evolution rates were similar to those previously reported for mangos (Burg and Burg,

Table 1. Effects of prestorage heat treatment on mango chilling injury ratings ${ }^{\mathrm{z}}$ following storage for 11 days at $5 \mathrm{C}$.

\begin{tabular}{lcc}
\hline & \multicolumn{2}{c}{ Chilling injury } \\
\cline { 2 - 3 } Hours at & \multicolumn{2}{c}{ Hours at 21C } \\
\cline { 2 - 3 } $38 \mathrm{C}$ & 0 & 48 \\
\hline 0 & $2.8^{\mathrm{y}}$ & 3.9 \\
24 & 1.3 & 1.4 \\
48 & 0.9 & 1.0 \\
Linear & $* * *$ & $* * *$ \\
Quadratic & $* *$ & $* * *$ \\
\hline
\end{tabular}

${ }^{\mathrm{z}}$ Chilling injury was rated on a scale of 0 to 4 , where $0=$ none, $1=$ trace, $2=$ slight, $3=$ moderate, and 4 $=$ severe.

${ }^{\mathrm{y}}$ Values are means of 40 fruit.

******Significant at $P=0.01$ or 0.001 , respectively.
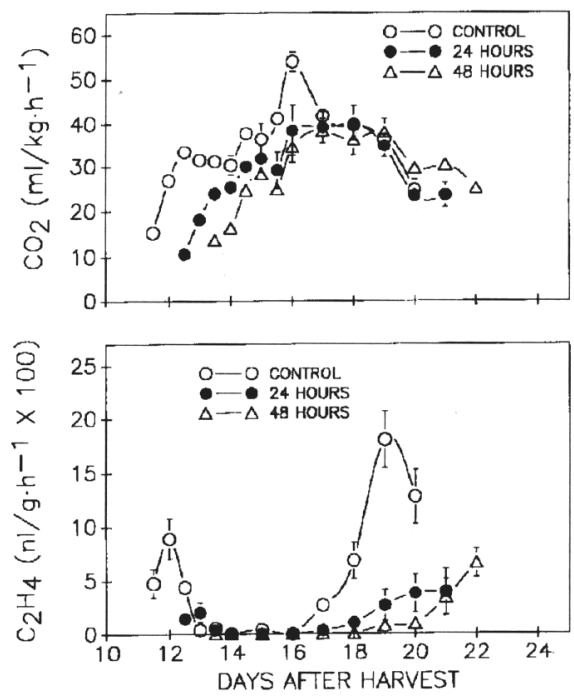

Fig. 1. Effects of heat treatment before storage at $5 \mathrm{C}$ on respiration rate (top) and ethylene evolution (bottom) from mango fruit at $21 \mathrm{C}$ following storage at $5 \mathrm{C}$ for 11 days. ( $\mathrm{O}$ ) Control (nonheated); ( $\bullet$ ) heated at 38C for $24 \mathrm{~h} ;(\Delta)$ heated at $38 \mathrm{C}$ for $48 \mathrm{~h}$. 
1962; Veloz et al., 1977). Carbon dioxide evolution pattern was similar in nonheated and heated fruit. When carbon dioxide production rate was compared based on the number of days after harvest, the rate was higher in nonheated than heated fruit. However, if respiratory rate was compared based on time after transfer to $21 \mathrm{C}$, the rates for nonheated and heated fruit were similar. Heat treatment reduced respiratory rates of chilled tomato (Lurie and Klein, 1991) and cucumber (Hirose, 1985).

In mangos, heat treatment apparently affected the timing, but not the magnitude of the respiratory climacteric.

Burg and Burg (1962) reported that ethylene rises when or before carbon dioxide production rises in ripening mangos, whereas Biale and Young (1981) included mango among the fruit in which ethylene rises after carbon dioxide rises. In the present study, nonheated fruit had a transient burst of ethylene evolution during the first $24 \mathrm{~h}$ after transfer to $21 \mathrm{C}$, but this burst did not occur in the heated fruit (Fig. 1, bottom). Ethylene evolution from nonheated fruit peaked 8 days after transfer to $21 \mathrm{C}$. Although heated fruit had a slight increase in ethylene evolution after 8 days at $21 \mathrm{C}$, the magnitude of the increase was about one-third that of the nonheated fruit. Ethylene evolution is inhibited at high temperatures but may exceed normal levels if fruit are transferred to a nonstressing temperature (Biggs et al., 1988; Lurie and Klein, 1991; Paull and Chen, 1990). Ethylene evolution typically is stimulated in chilling-sensitive commodities that have been stored at chilling temperatures for a short period after they are transferred to a nonchilling temperature; ethylene evolution is inhibited in fruit exposed to chilling temperatures for a long period (Field, 1990). Heated tomato fruit had higher ethylene evolution rates following storage for 3 weeks at 2C than nonheated controls (Lurie and Klein, 1991). In mango, the burst of ethylene produced by nonheated fruit the first $24 \mathrm{~h}$ after transfer to $21 \mathrm{C}$ was not detected in heated fruit. This result may indicate that the heat treatment effectively inhibited chilling-induced ethylene production.

Flesh firmness of control and heated mangos did not differ significantly at the time of transfer from 5 to $21 \mathrm{C}$ (0 days, Table 2$)$. All fruit softened extensively during the first 3 days at $21 \mathrm{C}$. Following 3 and 6 days at $21 \mathrm{C}$, heated fruit were significantly softer than control fruit. Fruit firmness did not differ significantly among treatments after 9 days at $21 \mathrm{C}$. Medlicott et al. (1990) reported that storing mangos at low temperatures reduced fruit softening. In the present study, heated fruit softened slightly faster than nonheated fruit. This result indicates that heat treatment may lessen the effect of chilling on softening.

Total SSC was higher in heated than in control fruit at the time of transfer to $21 \mathrm{C}$ and during the first 6 days of ripening; after 9 days of ripening, total SSC did not differ significantly among treatments (Table 2). SSC in all treatments was similar to that previously reported for 'Keitt' mangos from Florida by Spalding et al. (1988), but lower than that
Table 2. Effects of prestorage heat treatment on flesh firmness, total soluble solids concentration (SSC), and titratable acidity of mangos after removing them from storage (11 days at $5 \mathrm{C}$ ) and during ripening at $21 \mathrm{C}$.

\begin{tabular}{|c|c|c|c|c|}
\hline \multirow{2}{*}{$\begin{array}{l}\text { Hours at } \\
38 \mathrm{C}\end{array}$} & \multicolumn{4}{|c|}{ Days at $21 \mathrm{C}$} \\
\hline & 0 & 3 & 6 & 9 \\
\hline \multicolumn{5}{|c|}{ Flesh firmness $(N)$} \\
\hline 0 & 47.8 & 16.9 & 5.4 & 3.3 \\
\hline 24 & 71.6 & 12.1 & 4.0 & 3.3 \\
\hline 48 & 55.9 & 7.8 & 3.9 & 3.5 \\
\hline Linear & NS & $*$ & $* *$ & NS \\
\hline Quadratic & NS & NS & NS & NS \\
\hline \multicolumn{5}{|c|}{$S S C$} \\
\hline 0 & 5.7 & 8.3 & 10.9 & 11.6 \\
\hline 24 & 6.4 & 9.3 & 12.6 & 12.5 \\
\hline 48 & 8.9 & 11.1 & 12.3 & 11.8 \\
\hline Linear & $* *$ & $* *$ & $*$ & NS \\
\hline Quadratic & $* *$ & NS & * & NS \\
\hline \multicolumn{5}{|c|}{ Titratable acidity ${ }^{z}(\%)$} \\
\hline 0 & 0.76 & 0.72 & 0.56 & 0.30 \\
\hline 24 & 0.93 & 0.84 & 0.45 & 0.27 \\
\hline 48 & 0.95 & 0.79 & 0.49 & 0.21 \\
\hline Linear & $*$ & NS & NS & NS \\
\hline Quadratic & NS & NS & NS & $*$ \\
\hline
\end{tabular}

${ }^{\mathrm{z}}$ Expressed as anhydrous citric acid.

$\mathrm{NS}, * * *$ Nonsignificant or significant at $\mathrm{P}=0.05$ or 0.01 , respectively.

reported by Vazquez-Salinas and Lakshminarayana (1985). Storing mangos at low temperature decreased total SSC in ripe fruit (Krishnamurthy and Joshi, 1989).

At the time of transfer to $21 \mathrm{C}$, titratable acidity of mango fruit flesh was significantly lower in nonheated than heated fruit (Table 2). However, titratable acidity of all fruit decreased during ripening and was significantly lower in heated than nonheated fruit, but only after 9 days. Chilled mangos were more acidic than nonchilled mangos (Veloz et al., 1977), and heat-treating apples reduced fruit acidity (Lurie and Klein, 1990).

CIE $a^{*}$ and $b^{*}$ values of mango fruit flesh were influenced significantly by heat treatment (Table 3 ). Red (a* value) and yellow ( $b^{*}$ value) increased during fruit ripening in all treatments. However, mangos heated for $48 \mathrm{~h}$ had consistently higher $a^{*}$ and $b^{*}$ values than control fruit. This result indicates that more color developed in heated than in control fruit.

The most pronounced effect of high-temperature treatment on mango chilling tolerance in this study was reduced rind pitting and discoloration. This reduction was apparent at the time of transfer from 5 to $21 \mathrm{C}$ and persisted during ripening. Although CI symptoms on the rind were severe, nonheated and heated fruit ripened in a normal pattern, as indicated by changes in firmness, color, and composition. Our results indicate that heat treatment may improve the tolerance of mangos to chilling temperatures.

\section{Literature Cited}

Biale, J.B. and R.E. Young. 1981. Respiration and ripening in fruits-Retrospect and prospect, $\mathrm{p}$. 1-39. In: J. Friend and M.J.C. Rhodes (eds.). Recent advances in biochemistry of fruit and vegetables. Academic, London and New York.

Biggs, M.S., W.R. Woodson, and A.K. Handa. 1988. Biochemical basis of high-temperature inhibition of ethylene biosynthesis in ripening
Table 3. Effects of prestorage heat treatment on flesh color of mangos after removing them from storage ( 11 days at $5 \mathrm{C}$ ) and during ripening at $21 \mathrm{C}$.

\begin{tabular}{lcccc}
\hline Hours at & \multicolumn{5}{c}{ Days at 21C } \\
\cline { 2 - 5 } $38 \mathrm{C}$ & 0 & 3 & 6 & 9 \\
\hline \multicolumn{5}{c}{$a^{*}$ Value } \\
0 & -3.81 & -2.74 & -1.79 & 2.90 \\
24 & -2.98 & -2.58 & 1.89 & 5.55 \\
48 & -2.20 & -0.12 & 3.49 & 8.04 \\
Linear & $*$ & $*$ & $* *$ & $* *$ \\
& \multicolumn{5}{c}{$b^{*}$ Value } \\
0 & 44.1 & 51.0 & 53.9 & 56.1 \\
24 & 48.0 & 51.8 & 58.7 & 57.0 \\
48 & 52.7 & 56.7 & 58.3 & 60.4 \\
Linear & $*$ & $*$ & $*$ & $*$ \\
\hline$* *$ Significant at $P=0.01$ or 0.05 , respectively. \\
Quadratic effects were nonsigificant in all cases.
\end{tabular}

tomato fruit. Physiol. Plant. 72:572-578.

Burg, S.P. and E.A. Burg. 1962. Role of ethylene in fruit ripening. Plant Physiol. 37:179-189.

Couey, M.-H. 1986. Chilling injury in crops of tropical and subtropical origin. HortScience 17: 162165.

Field, R.J. 1990. Influence of chilling stress on ethylene production, p. 235-253. In: C.Y. Wang (ed.). Chilling injury of horticulturalcrops. CRC Press, Boca Raton,.Fla.

Hatton, T.T., W.F. Reeder, and C.W. Campbell. 1965. Ripening and storage of Florida mangos. U.S. Dept. Agr. Market Res. Rpt. 725:9.

Hirose, T. 1985. Effects of pre- and interposed warming on chilling injury, respiratory rate and membrane permeability of cucumber fruits during cold storage. J. Jpn. Soc. Hort. Sci. 53:459466.

Kane, O. M. Boulet, and F. Castaigne. 1982. Effect of chilling injury on texture and fungal rot of mangoes (Mangifera indica L.). J. Food Sci. 47:992-995

Klein, J.D. and S. Lurie. 1991. Postharvest heat treatment and fruit quality. Postharvest News Info. 2:15-19.

Krishnamurthy, S. and S.S. Joshi. 1989. Studies on low temperature storage of Alphonso mango. J. Food Sci. Technol. 24:177-180.

Lafuente, M.T., A. Belver, M.G. Guye, and M.E. Saltveit. 1991. Effect of temperature conditioning on chilling injury of cucumber cotyledons. Plant Phvsiol. 95:443-449.

Lurie, S. and J.D. Klein. 1991. Acquisition of lowtemperature tolerance in tomatoes by exposure to high-temperature stress. J. Amer. Soc. Hort. Sci. 116:1007-1012.

Medlicott, A.P., J.M.M. Sigrist, and O. Sy. 1990. Ripening of mangos following low-temperature storage. J. Amer. Soc. Hort. Sci. 115:430-434.

Paull, R.E. and N.J. Chen. 1990. Heat shock response in field-grown, ripening papaya fruit. J. Amer. Soc. Hort. Sci. 115:623-631.

Spalding, D.H., J.R. King, and J.L. Sharp. 1988. Quality and decay of mangos treated with hot water for quarantine control of fruit fly. Trop. Sci. 28:95-101.

Thomas, P. and M.R. Joshi. 1988. Reduction of chilling injury in ripe Alphonso mango fruit in cold storage by temperature conditioning. Intl. J. Food Sci. Technol. 23:447-455.

Vazquez-Salinas, C. and S. Lakshminarayana. 1985. Compositional changes in mango fruit during ripening at different storage temperatures. J. Food Sci. 50:1646-1648.

Veloz, C.S., F.E. Tortes, and S. Lakshminarayana. 1977. Effect of refrigerated storage temperatures on the incidence of chilling injury and ripening quality of mango fruit. Proc. Florida State Hort. Soc. 90:205-210. 